\title{
Pen Torch Transillumination: Difficult Venepuncture Made Easy
}

\author{
Sabaretnam Mayilvaganan ${ }^{1} \cdot$ Sapana Bothra $^{1} \cdot$ Aromal Chekavar $^{1} \cdot$ \\ Amit Agarwal ${ }^{1}$
}

Published online: 8 August 2017

(C) Société Internationale de Chirurgie 2017

We read with interest the article "Pen Torch Transillumination: Difficult Venepuncture Made Easy" by Cai et al. We congratulate the authors on their study on difficult venepuncture made easy making use of transillumination principle which can be replicated in any scenario [1-3]. We in our endocrine and breast surgery unit also encounter this practically difficult venepuncture especially in patients undergoing chemotherapy for carcinoma of the breast, Cushing's syndrome and paediatric patients. This cost-effective technique shall result in less distress for these highly difficult venepuncture, and we feel that routine use shall decrease the learning curve for this technique.

We have few queries which shall be of interest to the future readers. We would like to know whether the authors had to use dark to illuminate these veins well. In their practice, what percentage of these difficult venepunctures land up in central venous catheterization or venous cut down? Did the patients feel uncomfortable with the heat emitted from the pen torch since the average time of contact was almost 8 min?

\section{References}

1. Cai EZ, Sankaran K, Tan M, Chan YH, Lim TC (2017) Pen torch transillumination: difficult venepuncture made easy. World J Surg. doi:10.1007/s00268-017-4050-3

2. Kaewgun T, Anupongongarch P, Roongprasert K (2016) Design and construction of a compact model of median cubital vein transilluminator. In: Biomedical engineering international conference (BMEiCON), 9th 2016 Dec 7, IEEE, pp 1-5

3. John JM (2007) Transillumination for vascular access: old concept, new technology. Pediatr Anesth 17(2):197-198
Sabaretnam Mayilvaganan drretnam@gmail.com

1 Department of Endocrine and Breast Surgery, Sanjay Gandhi Postgraduate Institute of Medical Sciences, Lucknow, India 